\title{
Abnormal bony protuberance of anterior atlas causing dysphagia. A rare congenital anomaly
}

\author{
K Ílbay*,1, Ç Evliyaoğlu ${ }^{1}$, V Etus ${ }^{1}, \mathrm{H}$ Özkarakas ${ }^{2}$ and S Ceylan ${ }^{1}$ \\ ${ }^{1}$ Department of Neurosurygery, Kocaeli University Faculty of Medicine, Kocaeli, Turkey; ${ }^{2}$ Department \\ of Otorhinolaryngology, Kocaeli University Faculty of Medicine, Kocaeli, Turkey
}

Study design: A Case report.

Objective: To report an exceedingly rare case of dysphagia caused by abnormal bony protuberance of anterior atlas.

Setting: Kocaeli University Faculty of Medicine, Departments of Neurosurgery and Otorhinolaryngology.

Method: Radiological examinations revealed a large anterior abnormal bony tuberance of atlas in an 11-year-old boy who complained of dysphagia of 5 years donation.

Result: The anterior bony tuberance of the atlas was resected by a transoral approach. Histopathological examination of the surgical specimens showed normal bone tissue. Resection resulted in complete resolution of the dysphagia.

Conclusions: Dysphagia can be caused by disorders of the cervical spine. These disorders are usually seen in elderly adults. In the pediatric population, spinal abnormality is an exceedingly rare cause of dysphagia. Abnormal inductive signals from the adjacent notocord and ventral neural tube may play role in the pathogenesis of this abnormal bony protuberance.

Spinal Cord (2004) 42, 129-131. doi:10.1038/sj.sc.3101549

Keywords: atlas; bony tuberance; dysphagia

\section{Introduction}

A case of a pediatric patient having dysphagia due to an abnormal bony protuberance of atlas is reported. The lesion was surgically removed. The radiological findings, differential diagnosis and physiopathological mechanisms of the bony protuberance are discussed.

\section{Case report}

This 11-year-old boy was admitted to our hospital with complaints of difficulty in eating solid foods for 5 years. In his physical examination, a midline hard mass was palpated in the retropharyngeal region. Lateral cervical X-ray (Figure 1a) and computed tomography scans of the cervical spine (Figure 1b) revealed a large abnormal bony protuberance of atlas originating from its anterior tubercle that impinged upon the pharynx. Radiological examinations were normal for thoracic and lumbosacral vertebrae. Also, radiological examinations of both the upper and lower extremities and cranium showed no abnormalities. The

*Correspondence: K Ilbay, Fatih Mahallesi, Cumhuriyet Caddesi, Doktorlar Sitesi, F Blok, Da: 3, Kurucesme, 41100 Kocaeli, Turkey anterior bony protuberance of atlas was surgically resected by a transoral approach. No gross morphological difference between the bony protuberance and anterior arch of atlas was observed during resection. Histopathological examination of the specimen revealed normal bone tissue. Dysphagia of the patient disappeared after surgery. Control X-ray (Figure 2a) and bone-window computed tomography (Figure 2b) examinations confirmed the decompression achieved after resection of the bony tuberance.

\section{Discussion}

Dysphagia due to external compression by anterior hyperostosis of the cervical spine is rare. Cervical vertebral pathologies that can cause dysphagia by osteophyte formation are degenerative joint disease, ankylosing spondylosis, diffuse idiopathic skeletal hyperostosis (Forestier disease) and hereditary multiple exostosis. ${ }^{1-4}$ These pathologies are usually seen in elderly adults especially after the age of 60 years. However, such a morphological change in cervical vertebra is extremely rare in children. To the best of our knowledge, to date, only one case has been reported 

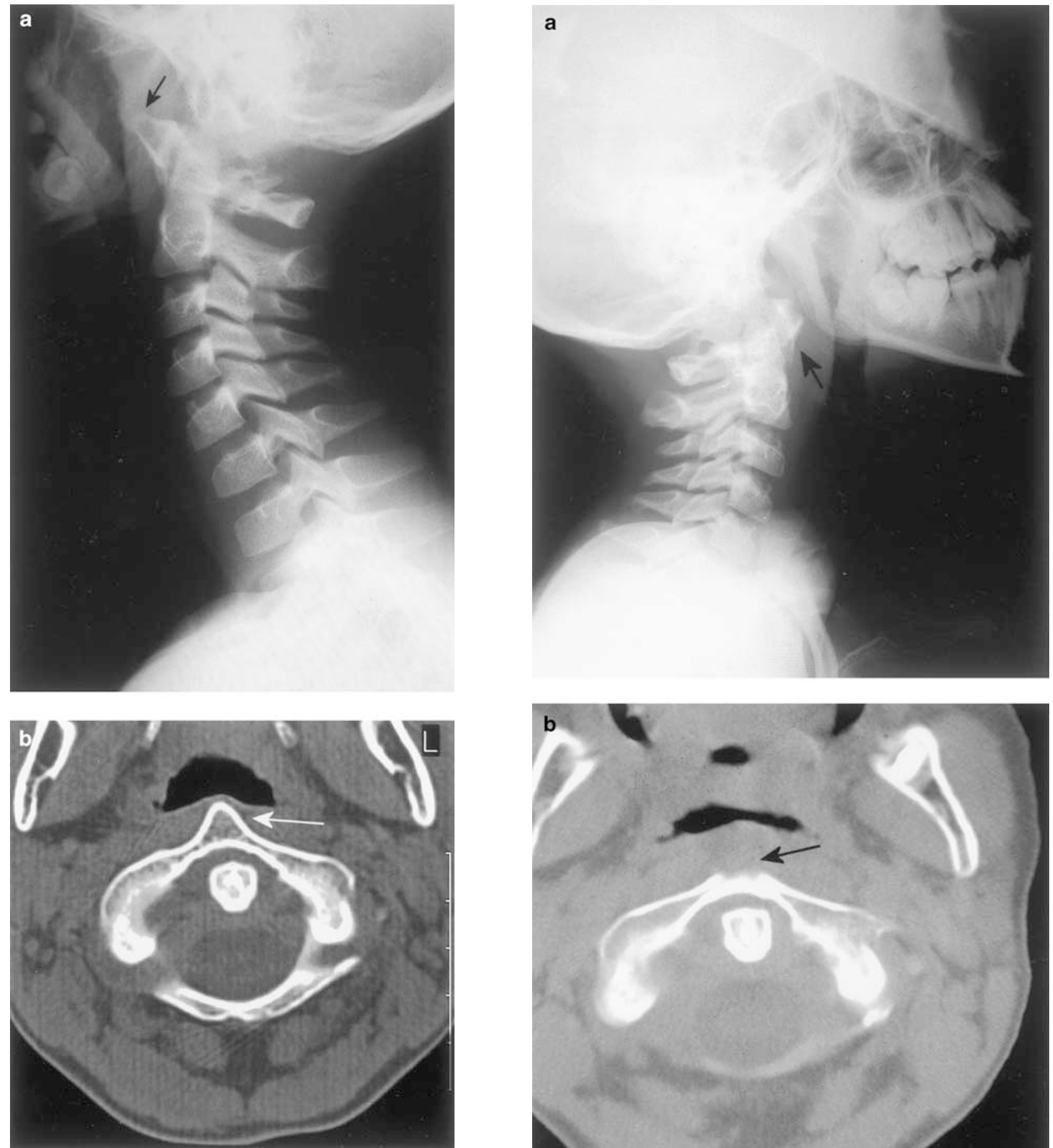

Figure 1 (a) Lateral cervical X-ray shows the anterior abnormal bony protuberance (arrow) of atlas. (b) Bonewindow computed tomography scan, revealing a large abnormal bony protuberance of atlas (arrow) originating from its anterior tubercle, which impinged upon the pharynx

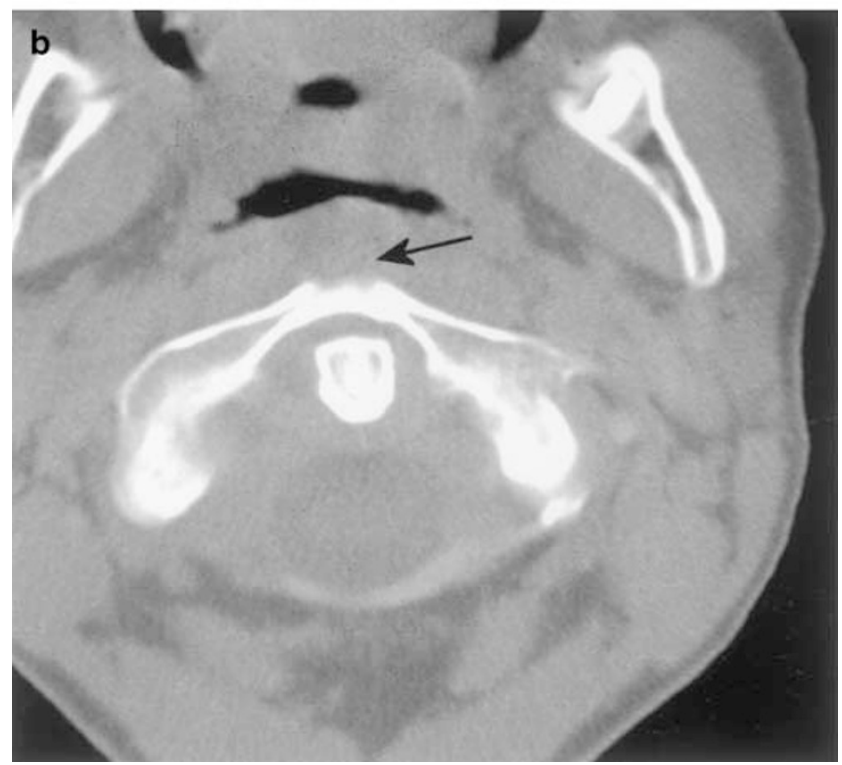

Figure 2 (a) Lateral cervical X-ray reveals that anterior abnormal bony protuberance of atlas was resected (arrow). (b) Postoperatively obtained bone-window computed tomography scan, which shows decompression after the abnormal bony protuberance of atlas was resected (arrow)

in the literature. In the report, Barros et al have described a pediatric case in which hereditary multiple exostosis in cervical vertebrae had caused dysphagia. ${ }^{5}$ Our case is unique because it represents the only

recorded instance of a solitary congenital abnormality of the protuberance of atlas, with no family history for inheritance and without any history of trauma, inflammation or endocrinological disease. We entertained 
other diagnostic possibilities, but none fit the clinical or radiological characteristics of the lesion described in this report. An exostosis or osteochondroma should have a cartilaginous cap. A healed callus will have an irregular outline and may not be as perfectly smooth as that observed in our patient and there was no antecedent history or documentation of any trauma or fracture.

Dysphagia in our case was thought to be caused either by mechanical obstruction or by paraesophageal inflammation due to irritation caused by the hyperosteotic process.

The atlas usually develops from one ossification center in the vertebral body and two centers in the neural arches. The neurocentral synchondroses usually fuse at about 7 years of age. ${ }^{6}$ The characteristic development of specific vertebrae seems to be related to the intrinsic properties of their particular somatic precursors. The segmentation and differentiation of these somatic subunits are under the control of regulatory genes and growth factors that act through specific inductive mechanisms. ${ }^{7}$ With variable cell migration, segmentation and ossification, it is possible to anticipate the presence of numerous variants. In our case, it is also plausible that abnormal inductive signals from the adjacent notochord and ventral neural tube might have induced the development of such an abnormal protuberance.

\section{References}

1 Escobar C, Amores A, Gonzalez Moscoso P, Redondo R. Dysphagia as a symptom of diffuse idiopathic skeletal hyperostosis (Forestier-Rotes disease). A case report and literature review. Acta Otorrinolaringol Esp 1997; 48: 161-163.

2 Grasshoff H, Motsch C, Mahlfeld K. Vertebragenic dysphagia. Zentralbl Chir 1999; 124: 1041-1044.

3 Krause P, Castro WH. Cervical hyperostosis: a rare cause of dysphagia. Case description and bibliographical survey. Eur Spine J 1994; 3: 56-58.

4 McGarrah PD, Teller D. Posttraumatic cervical osteophytosis causing progressive dysphagia. South Med J 1997; 90: 858-860.

5 Barros Filho TE, Oliveira RP, Taricco MA, Gonzales CH. Hereditary multiple exostoses and cervical ventral protuberance causing dysphagia. A case report. Spine 1995; 20: 1640 1642.

6 Naidich TP et al. ongenital anomalies of the spine and spinal cord. In: Scott WA (ed) Magnetic Resonance Imaging of the Brain and Spine, 3rd edn. Lippincott Williams \& Wilkins: Philadelphia 2002 pp 1527-1631.

7 Larsen WJ. Human Embryology, 3rd edn, Churchill Livingstone: Philadelphia, 2001. 